\title{
Consolidation of MA W-Ni-Fe Alloyed Powder by Microwave-Assisted Sintering
}

\author{
Wensheng Liu, Yunzhu Ma, Qingshan Cai \\ State Key Laboratory for Powder Metallurgy, Central South University, Changsha, China. \\ Email: zhuzipm@mail.csu.edu.cn \\ Received February $17^{\text {th }}, 2011$; revised March 21 $1^{\text {st }}, 2011$; accepted April 12 $2^{\text {th }}, 2011$.
}

\begin{abstract}
MA W-Ni-Fe alloyed powder compact was sintered by microwave technology, and the influence of microwave sintering on consolidation of W-Ni-Fe alloy was studied. The fracture morphology and microstructure of alloys were measured by SEM and metallurgical microscope. The experimental results showed that microwave sintering promoted the densification of MA W-Ni-Fe alloyed powder quickly with the higher heating rate. The density of the sintered samples increased with the increase of sintering temperature, and significant densification shrinkage occured at $1300^{\circ} \mathrm{C} \sim 1400^{\circ} \mathrm{C}$. The tungsten grain grew rapidly at $1450^{\circ} \mathrm{C}$. When the alloy was microwave sintered at $1550^{\circ} \mathrm{C}$, the inner structure of alloy is more homogeneous, the average $W$ grain size is about $15 \mu \mathrm{m}$, and the relative density of sintered specimen is $99 \%$.
\end{abstract}

Keywords: W-Ni-Fe Alloy, Microwave Sintering, Consolidation

\section{Introduction}

Tungsten heavy alloys (WHAs) have a series of excellent physical and mechanical properties, such as high density, high strength, good electrical and thermal conductivity, good radiation absorption capacity, low linear expansion coefficient, good weldability, good mechining properties, etc. Therefore, WHAs are widely used in high technology fields, especially in the military industry. With the rapid development of science and technology, the more and more requirements to the properties of WHAs are put forward. So new research on WHAs considered by material scientists has become a hotspot in recent years.

Tungsten heavy alloys are usually consolidated through liquid phase sintering. However, during liquid sintering, solid/liquid phase easily produce viscous flow, segregation, and even cause collapse and deformation because of the large difference in density between $\mathrm{W}$ phase and binder phase. In recent years, in order to control liquid sintering collapse and gain high proportion of tungsten heavy alloys, solid-phase sintering, two-stage sintering and activated sintering of tungsten-based alloys have been studied deeply [1-5].

Microwave sintering technology, with the heat generated by a combination of the special wave band and the basic fine structure of the material, is a method to achieve densification of the material which is heated to the required temperature by means of the dielectric loss. Compared with the traditional heating process, the heating efficiency of microwave is mainly come from the polarization of the alternating electromagnetic field, which makes the dipoles of inner material turning around repeatedly, resulting in a stronger vibration and friction, thereby heating the material [6]. Microwave sintering has a lot of merits, such as energy and time saving [7-10], and reducing production cost and energy consumption is of great significance, so that it has considerable prospective potential when it is introduced into production manufactures of powder metallurgy materials. But the traditional views indicated that the metal reflects microwave as a conductor, so the microwave could not be used to heat the metal. Until 1999, it was first reported using microwave sintering technology to achieve the sintering of iron-base powder metallurgy parts [11]. In recent years, the microwave sintering of metal and alloy have been researched as a popular problem. G. Prabhu [12] have studied the sinterability of tungsten powder in microwave and the density of $93 \%$ of TD was gained. Similarly, tungsten heavy alloys $(92.5 \mathrm{~W}-6.4 \mathrm{Ni}-1.1 \mathrm{Fe})$ have also been sintered in microwave and were found to have better hardness, tensile strength and elongation when compared to conventionally sintered heavy alloy [13].

The main objective of the present study is to investigate 
the consolidation of MA W-Ni-Fe alloyed powder and microstructure response during microwave assisted sintering.

\section{Experimental}

Powders (as shown in Table 1) were mechanically alloyed in a high energy ball mill for $20 \mathrm{~h}$ with the composition of $93 \mathrm{~W}-4.9 \mathrm{Ni}-2.1 \mathrm{Fe}(\mathrm{wt} \%)$.

The mechanically alloyed composite powders were pressed into green tensile compacts by hydraulic press (YH41-25C). After pretreatment, the green compacts were sintered in a microwave furnace with frequency of $2.45 \mathrm{GHz}$ (HAMiLab-V6). At the heating rate of $30^{\circ} \mathrm{C} /$ $\mathrm{min}$, the whole sintering process was carried out at various sintering temperatures ranging from 1250 to $1500^{\circ} \mathrm{C}$ for $5 \mathrm{~min}$ in a flowing reducing atmosphere $\left(10 \mathrm{vol} . \% \mathrm{H}_{2}\right.$ and 90 vol. $\% \mathrm{~N}_{2}$ ). The density of the sintered specimens was characterized by the Archimedes principle. The tensile fracture morphology was observed by SEM (JSM$6360 \mathrm{LV}$ ). The sintered specimens were polished by automatic polishing machine, and then, etched. The optical microstructure was observed by optical microscopy (MeF3A).

\section{Results and Discussion}

\subsection{Densification Behaviour}

In the sintering process of powder metallurgy materials, sintering temperature and sintering time are the key factors to the densification of sintered compact. Figure 1 shows the influence of sintering temperature on the densification behavior of $93 \mathrm{~W}-\mathrm{Ni}-\mathrm{Fe}$ sintered compact. It is found that the densities of the sintered samples increase with the increase of sintering temperature, and significant densification shrinkage occurs at $1300^{\circ} \mathrm{C} \sim 1400^{\circ} \mathrm{C}$. Because W-Ni-Fe alloy has an eutectic temperature of $1460^{\circ} \mathrm{C}$, it is solid-phase sintering when the sintering temperature is below $1460^{\circ} \mathrm{C}$. By solid phase sintered at $1450^{\circ} \mathrm{C}$ by microwave, the relative density of the sample sintered could reach $98.6 \%$, and the effect of high densification of solid phase sintering is realized. Jain [14] revealed that high density materials could be obtained for pure $\mathrm{W}$ by microwave sintering in short time, which indicated that microwave had great effect on $\mathrm{W}$ particle re-arrangement and $\mathrm{W}$ atom diffusion. Microwave sintering can accelerate atomic diffusion significantly [15], and achieve the rapid densification of samples. During sintering process from $1400^{\circ} \mathrm{C}$ to $1450^{\circ} \mathrm{C}$, the connected skeleton forms and compact densification occur rapidly, and formation of $\gamma-(\mathrm{Fe}, \mathrm{Ni})$ phase, the diffusion of $\mathrm{W}$ in $\gamma$-(Fe,Ni) phase, the self-diffusion of $\mathrm{W}$, and the void and defect diffusion occur quickly because of microwave
Table 1. Performance parameter of raw powder.

\begin{tabular}{cccc}
\hline Powder & Powder shape & Particle size $(\mu \mathrm{m})$ & Powder purity (\%) \\
\hline $\mathrm{W}$ & Irregular & 2.0 & 99.9 \\
$\mathrm{Ni}$ & Spherical & $5 \sim 8$ & 99.5 \\
$\mathrm{Fe}$ & Irregular & $5 \sim 8$ & 99.5 \\
\hline
\end{tabular}

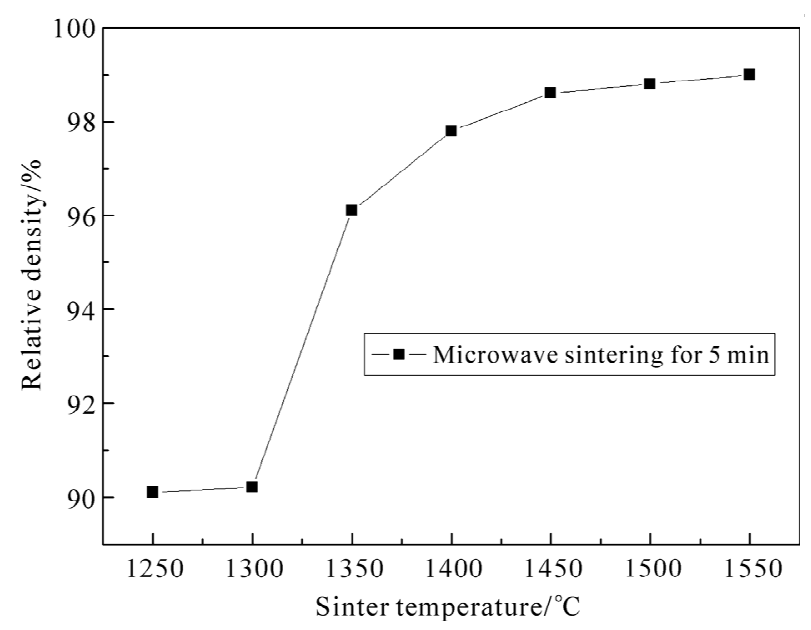

Figure 1. Effects of microwave-sintering temperature on densification of $93 \mathrm{~W}-\mathrm{Ni}-\mathrm{Fe}$ alloys.

field activation. When the temperature reach $1500^{\circ} \mathrm{C}$, the sintering process is liquid phase sintering, which increase the dissolution and precipitation process of $\mathrm{W}$ in binder phase. The formation of a lot of liquid phase and the effect of capillary force lead to the combination and growth of grains, the liquid phase infiltrations in $\mathrm{W}$ grain boundary and the void is filled, which make the sintered compact further densification.

\subsection{Microstructure Analysis}

\subsubsection{SEM Morphology Features}

Figure 2 shows the microstructure of $93 \mathrm{~W}-\mathrm{Ni}-\mathrm{Fe}$ alloys sintered at $1250^{\circ} \mathrm{C} \sim 1550^{\circ} \mathrm{C}$ for $5 \mathrm{~min}$ via microwave sintering. As can be seen from the graph, when the temperature is lower (Figures 2(a) and (b)), there are big porosities between powder compacts, and the sintered compact is in the early stage of solid-phase sintering, at that moment, the diffusion process is carried out, grains start to contact, and the sintering neck begin to form. With the sintering temperature increase, the sintering neck grow, the big porosities between powder compacts eliminate, $\gamma-(\mathrm{Fe}, \mathrm{Ni}, \mathrm{W})$ phase is precipitated and generated constantly, binder phase increase and $\mathrm{W}$ grains are separated gradually. When the temperature reach liquid sintering temperature (Figure 2(f)), a large number of liquid phases are generated and $\mathrm{W}$ grains are sphericized. Homogeneous microstructure of sintered 


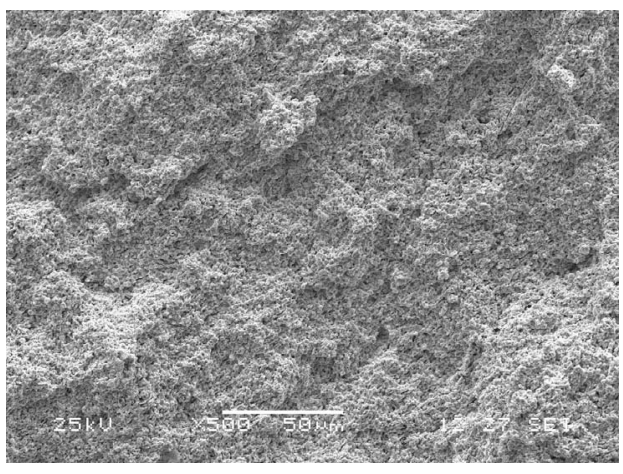

(a)

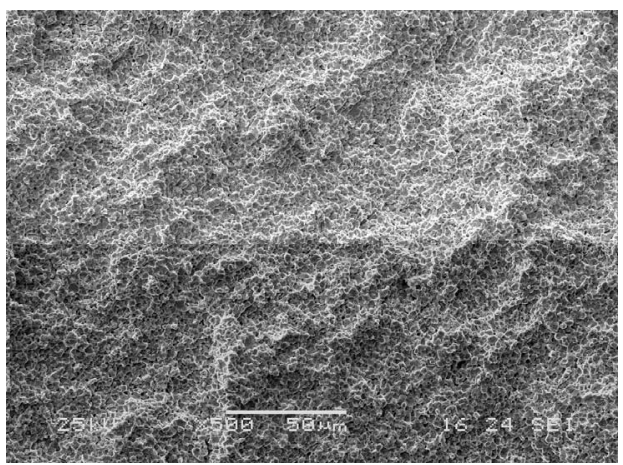

(c)

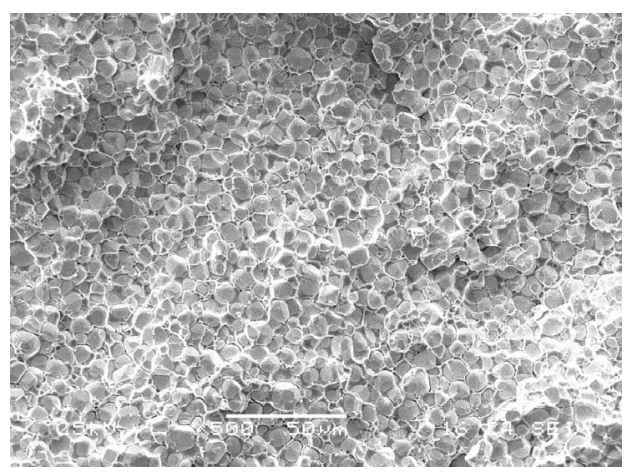

(e)

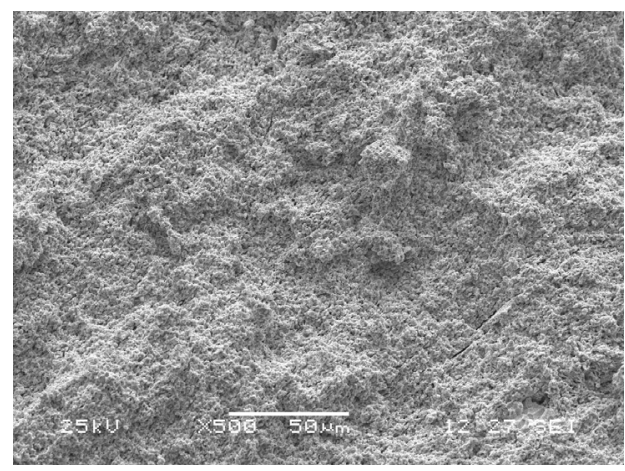

(b)

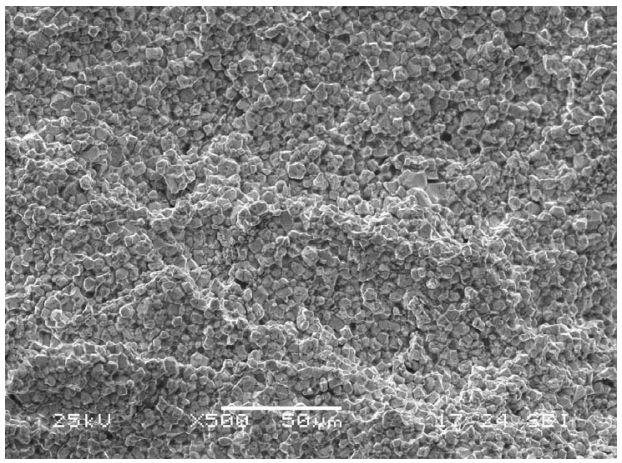

(d)

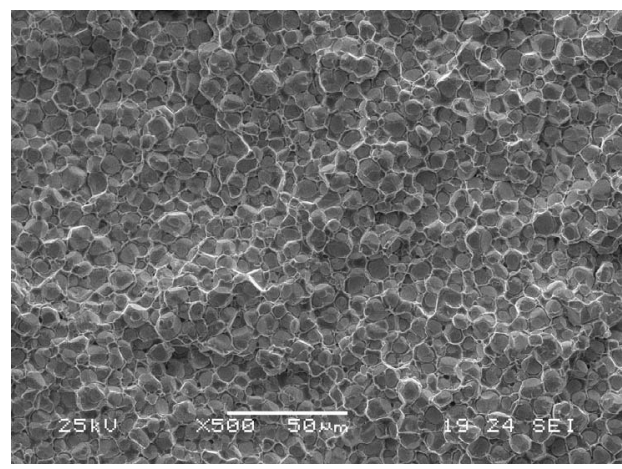

(f)

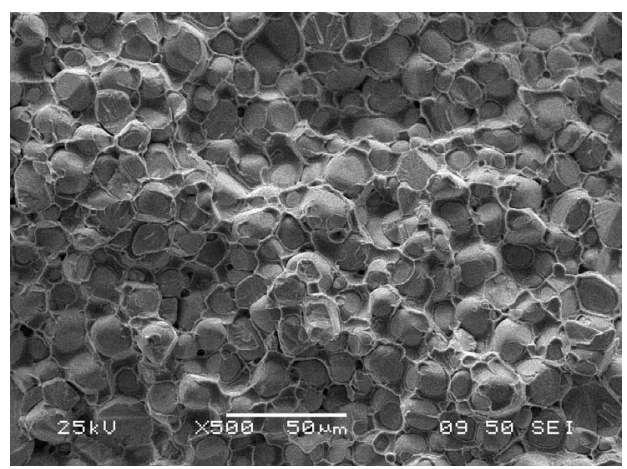

(g)

Figure 2. SEM image of alloy specimens microwave sintered at different temperatures: (a) $1250^{\circ} \mathrm{C}$; (b) $1300^{\circ} \mathrm{C}$; (c) $1350^{\circ} \mathrm{C}$; (d) $1400^{\circ} \mathrm{C}$; (e) $1450^{\circ} \mathrm{C}$; (f) $1500^{\circ} \mathrm{C}$; and (g) $1550^{\circ} \mathrm{C}$. 
samples with fine grains are obtained by microwave sintering at $1500^{\circ} \mathrm{C}$. This is reason why the microwave sintering process is the material as a whole coupled with microwave heating, is a "volume heating", is a more uniform temperature distribution, leads to the more evenly sintering of the grains [6]. On the other hand, the microwave sintering holding time is only $5 \mathrm{~min}$, the pore of samples diffusion time is short, which generates results in fine grains in alloys. When the sintering temperature is $1550^{\circ} \mathrm{C}$ (Figure $2(\mathbf{g})$ ), as can be seen that the grain size of microwave sintered samples grows significantly, while relative density of specimen reaches $99.0 \%$.

\subsubsection{Metallographic Structure Analysis}

Figure 3 shows the metallurgical microstructure of $93 \mathrm{~W}-\mathrm{Ni}-\mathrm{Fe}$ alloys sintered at $1250^{\circ} \mathrm{C} \sim 1550^{\circ} \mathrm{C}$ for $5 \mathrm{~min}$ via microwave sintering. As can be seen from the figure, when the sintering temperature $\left(1250^{\circ} \mathrm{C} \sim 1300^{\circ} \mathrm{C}\right)$ is low, the powder particle is small, with complex shape and irregular arrangement. When the temperature rises from $1300^{\circ} \mathrm{C}$ to $1400^{\circ} \mathrm{C}$, significant densification shrinkage occurs, the relative density of sintered samples increases from $90.2 \%$ to $98 \%$. According to the modern sintering theory, sintering densification of tungsten heavy alloys in solid-state sintering stage occurs under the comprehensive effect factors, such as the interaction of defects and defect expanding, the reduction of surface energy caused by diffusion, the formation of diffusion driving force and pore migration, mutual diffusion of elements, formation of the connected W skeleton, and so on.

When microwave sintering temperature is at $1450^{\circ} \mathrm{C}$, the densification of sintered samples reaches a high value and the density is $98.6 \%$. There is an obvious phenomenon of growth on $\mathrm{W}$ grains. W grain growth is realized through the solid-state diffusion of $\mathrm{W}$ atoms because of microwave field activation. Microwave sintering can effectively reduce the energy barrier of $\mathrm{W}$ atom diffusion, and can significantly increase the speed of atomic diffusion which accelerates the grain growth [15]. In addition, microwave sintering is in order to realize the internal and external material uniform heating, which depends on the transforming microwave energy absorbed by material itself into kinetic energy and potential energy of the inner material. Under the action of microwave electromagnetic energy, atomic diffusion accelerates, which promoting the activation of sample grain, decreasing the reaction activation energy, reducing the reaction temperature and speeding up the reaction. That results in a small amount of liquid formation of the microwave sintered samples below the liquid temperature, the formation of liquid-phase and the role of capillary force will lead to the consolidation and growth of grain.

When the sintering temperature is at $1500^{\circ} \mathrm{C} \sim 1550^{\circ} \mathrm{C}$, the sintered body is in the state of liquid phase sintering. The generation of liquid and the role of capillary force lead to liquid infiltrating in $\mathrm{W}$ grain boundary and growth of $\mathrm{W}$ grains, so that pores are filled and densification is further improved. From Figure 3(f), it can be seen that the distribution of tungsten grains in the matrix phase is not uniform, because liquid flowing and particle rearrangement are carried out insufficiently due to short sintering time. And the particle shape is irregular, with a large number of angular-shaped particles, and particle size and binder distributing are all not uniform. When the temperature rises to $1550^{\circ} \mathrm{C}$ (Figure $3(\mathrm{~g})$ ), the tungsten grains and matrix phase are distributed more evenly, and the contact between the tungsten grains is closer and the grain size is more uniform, the average $\mathrm{W}$ grain size is $15 \mu \mathrm{m}$, the shape of grain is nearly spherical, the relative density of the alloy is up to $99 \%$. This is because the sintering temperature increases, and the formation of a lot of liquid phase, the migration and rearrangement of $\mathrm{W}$ grains, as well as the late solution and precipitation are quite sufficient. In the dissolution-precipitation process, small particles solve first, the solubility of the sharp corners part and the convex part are greater than the solubility of the concave part and the rounded part in large particle, which results in the preferential solution of these parts. When the solubility in the liquid is saturated, the precipitation will occur at the concave part, so that $\mathrm{W}$ grains grow into a nearly circular structure. On the other hand, $\mathrm{W}$ element is an isometric system with a bodycentered cubic crystal structure, it has the same dissolution-precipitation rate in all directions, so spherical structure grains are easy to form.

\section{Conclusions}

1) Microwave sintering technology can also be used to prepare the W-Ni-Fe material, when compared with conventional sintering, it has a significant advantage with the faster heating rate and the shorter sintering cycle.

2) The microwave sintered $93 \mathrm{~W}-\mathrm{Ni}-\mathrm{Fe}$ samples have significant densification shrinkage at $1300^{\circ} \mathrm{C} \sim 1400^{\circ} \mathrm{C}$. After solid state sintering by microwave processing at $1450^{\circ} \mathrm{C}$, the relative density of sintered samples is up to $98.6 \%$, but there is an obvious phenomenon of grain growth.

3) The inner structure of microwave liquid phase sintered samples is more homogeneous at $1550^{\circ} \mathrm{C}$, and the average grain size of the nearly spherical tungsten is about $15 \mu \mathrm{m}$, the relative density of the sample sintered can reach $99 \%$.

\section{Acknowledgements}

The author thank National Natural Science Foundation of China (No. 50774098) and Creative research group of 


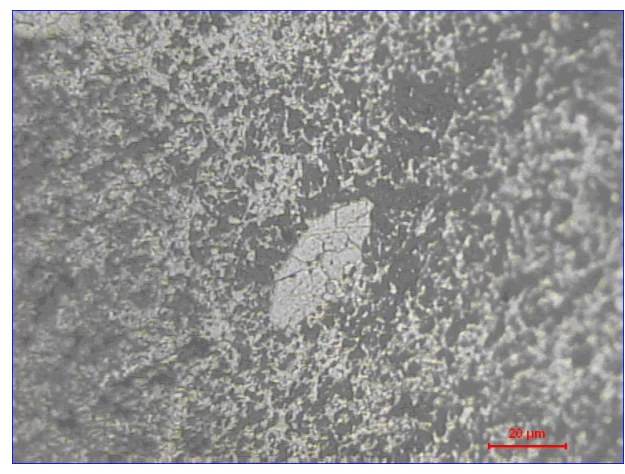

(a)

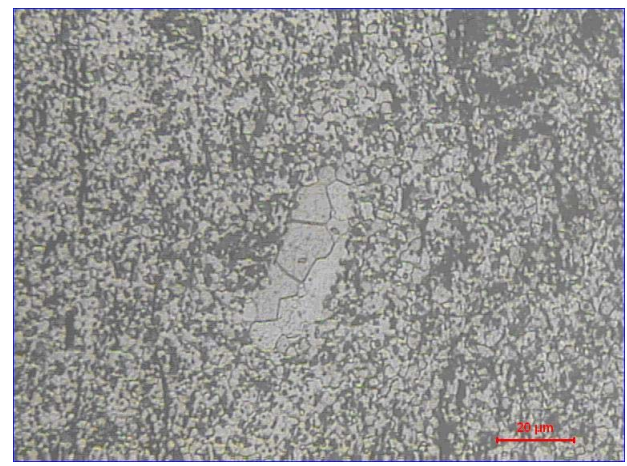

(c)

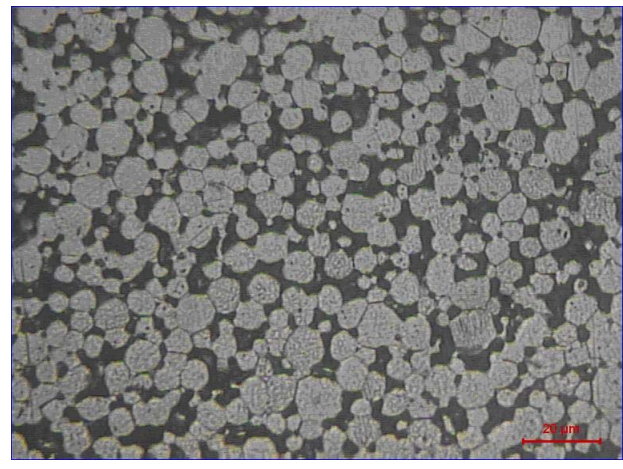

(e)

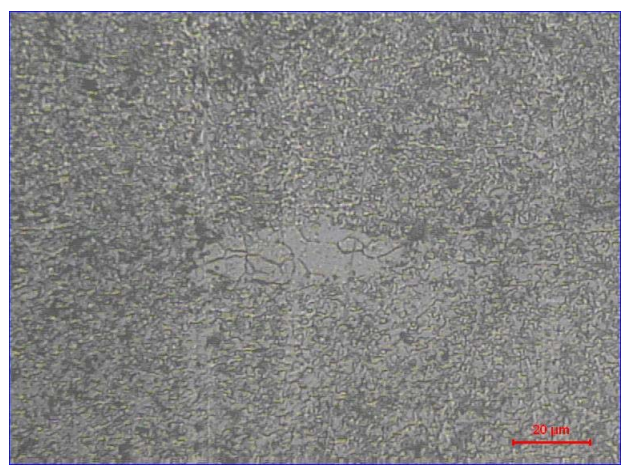

(b)

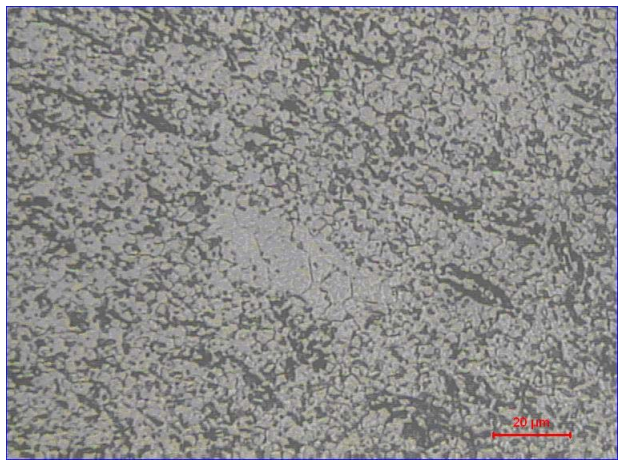

(d)

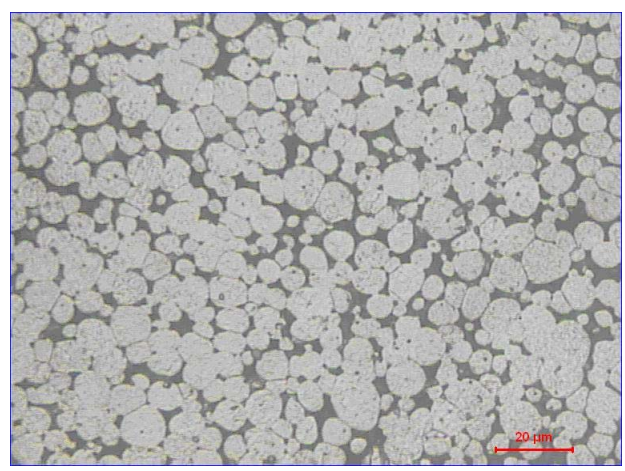

(f)

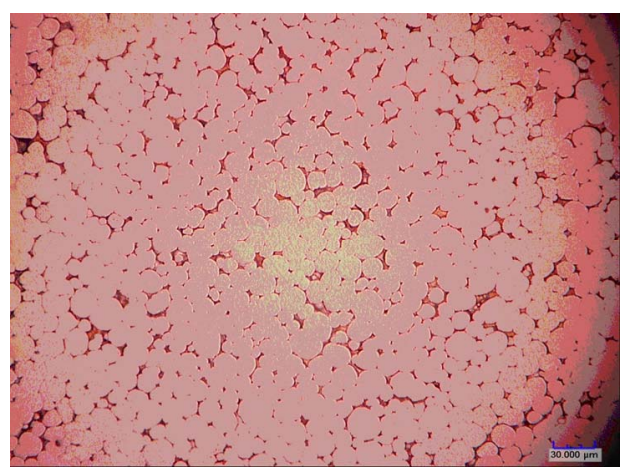

(g)

Figure 3. Optical photographs of alloy specimens microwave sintered at different temperatures: (a) $1250^{\circ} \mathrm{C}$; (b) $1300^{\circ} \mathrm{C}$; (c) $1350^{\circ} \mathrm{C}$; (d) $1400^{\circ} \mathrm{C}$; (e) $1450^{\circ} \mathrm{C}$; (f) $1500^{\circ} \mathrm{C}$; and (g) $1550^{\circ} \mathrm{C}$. 
National Natural Science Foundation of China (Grant No. 50721003) for financial support.

\section{REFERENCES}

[1] J. S. C. Jang, J. C. Fwu, L. J. Chang, G. J. Chen and C. T. Hsu, "Study on the Solid-Phase Sintering of the NanoStructured Heavy Tungsten Alloy Powder," Journal of Alloys and Compounds, Vol. 434-435, 2007, pp. 367-370. doi:10.1016/j.jallcom.2006.08.215

[2] F. Akhtar, "An Investigation on the Solid State Sintering of Mechanically Alloyed Nano-Structured 90W-Ni-Fe tungsten Heavy Alloy," International Journal of Refractory Metals and Hard Materials, Vol. 26, No. 3, May 2008, pp. 145-151.

[3] S. H. Hong and H. J. Ryu, "Combination of Mechanical Alloying and Two-Stage Sintering of a 93W-5.6Ni-1.4Fe Tungsten Heavy Alloy," Materials Science and Engineering A, Vol. 344, No. 1-2, March 2003, pp. 253-260.

[4] K. H. Lee, S. I. Cha, H. J. Ryu and S. H. Hong, "Effect of Two-Stage Sintering Process on Microstructure and Mechanical Properties of ODS Tungsten Heavy Alloy," Materials Science and Engineering: A, Vol. 458, No. 1-2, June 2007, pp. 323-329.

[5] X. Q. Li, H. W. Xin, K. Hu and Y. Y. Li, "Microstructure and Properties of Ultra-Fine Tungsten Heavy Alloys Prepared by Mechanical Alloying and Electric Current Activated Sintering," Transactions of Nonferrous Metals Society of China, Vol. 20, No. 3, March 2010, pp. 443-449.

[6] S. Das, A. K. Mukhopadhyay, S. Datta and D. Basu, "Prospects of Microwave Processing: An Overview," Bulletin of Materials Science, Vol. 32, No. 1, February 2009, pp. 1-13.

[7] A. Upadhyayaa and G. Sethi, "Effect of Heating Mode on the Densification and Microstructural Homogenization Response of Premixed Bronze," Scripta Materialia, Vol.
56, No. 6, March 2007, pp. 469-472.

[8] A. Upadhyaya, S. K. Tiwari and P. Mishra, "Microwave Sintering of W-Ni-Fe Alloy," Scripta Materialia, Vol. 56, No. 1, January 2007, pp. 5-8.

[9] M. Mazaheri, A. M. Zahedi and M. M. Hejazi, "Pro- cessing of Nanocrystalline $8 \mathrm{~mol} \%$ Yttria-Stabilized Zirconia by Conventional, Microwave-Assisted and Two- -Step Sintering," Materials Science and Engineering A, Vol. 492, No. 1-2, September 2008, pp. 261-267.

[10] S. S. Panda, V. Singh, A. Upadhyaya and D. Agrawal, "Sintering Response of Austenitic (316 L) and Ferritic (434 L) Stainless Steel Consolidated in Conventional and Microwave Furnaces," Scripta Materialia, Vol. 54, No. 12, June 2006, pp. 2179-2183

[11] R. Roy, D. Agrawal, J. Cheng and S. Gedevanishvili, "Full Sintering of Powder Metal Bodies in a Microwave Field," Nature, Vol. 399, No, 6737, June 1999, pp. 668670.

[12] G. Prabhu, A. Chakraborty and B. Sarma, "Microwave Sintering of Tungsten," International Journal of Refractory Metals and Hard Materials, Vol. 27, No. 3, May 2009, pp. 545-548.

[13] A. Upadhyaya, S. K. Tiwari and P. Mishra, "Microwave Sintering of W-Ni-Fe Alloy," Scripta Materialia, Vol. 56, No. 1, January 2007, pp. 5-8.

[14] M. Jain, G. Skandan, K. Martin, K. Cho, B. Klotz, R. Dowding, D. Kapoor, D. Agkawal and C. Jiping, "Microwave Sintering: A New Approach to Fine-Grain Tungsten: I," International Journal of Powder Metallurgy, Vol. 42, No.2, 2006, pp. 45-50.

[15] Z. Xie, J. Yang and Y. Huang, "Densification and Grain Growth of Alumina by Microwave Processing," Materials Letters, Vol. 37, No. 4-5, November 1998, pp. 215 220. 